\author{
دراسة اقتصادية لمعامل التفريخ بححافظة الثرقية \\ د/ إيمان رجب حسن سليمان \\ د/ تهاني صالح محمد بيومي يوسف درافه الفياليه \\ باحث \\ باحث أول
}

معهد بحوث الاقتصاد الزراعي- مركز البحوث الزراعية

Corresponding Author: Dr_tahany_saleh@yahoo.com

مقدمة: تعتبر معامل التفريخ أحد أهم حلقات صناعة الدواجن في مصر ركما أنها تعد المحدد المباشر لحجم المعروض من كتاكيت التربية في

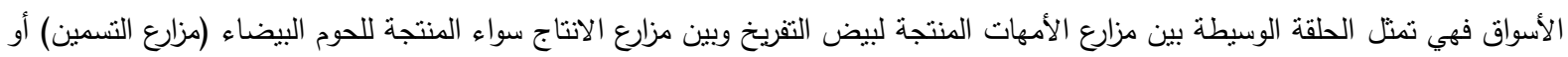

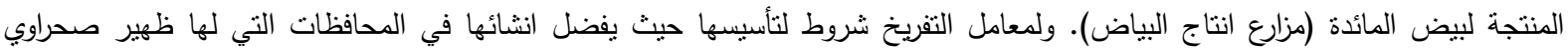

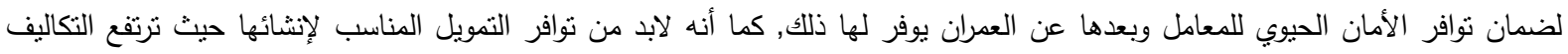

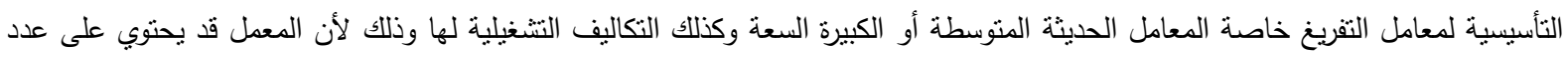

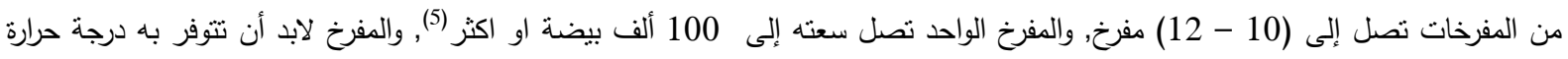

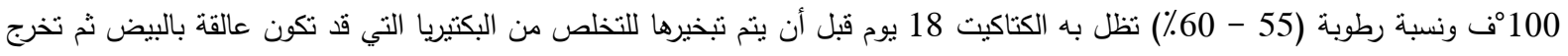

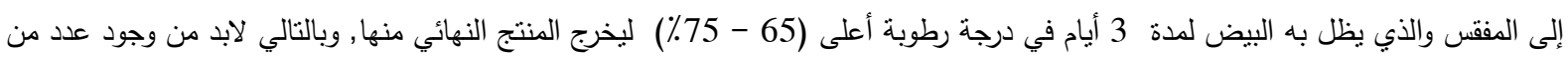

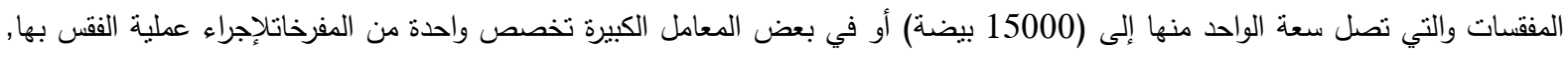

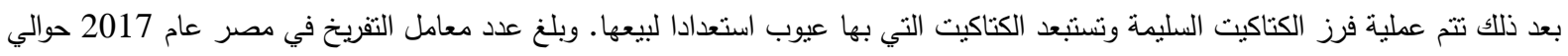

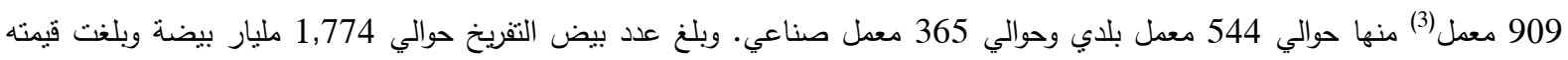

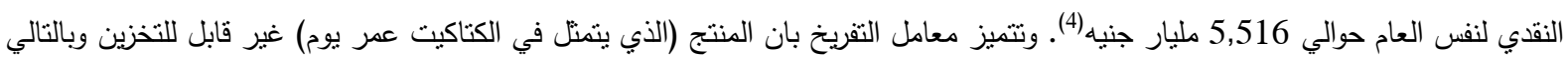

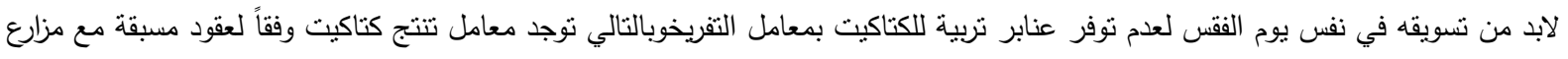

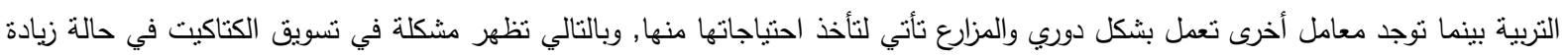

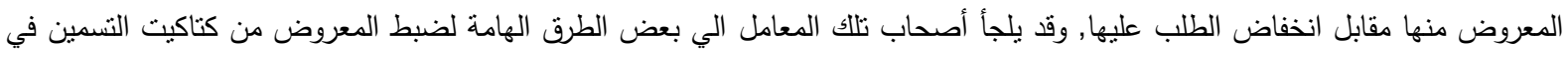

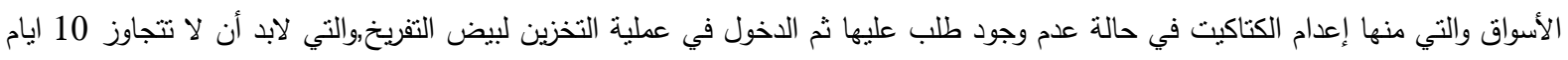

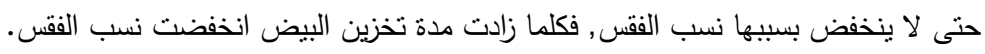

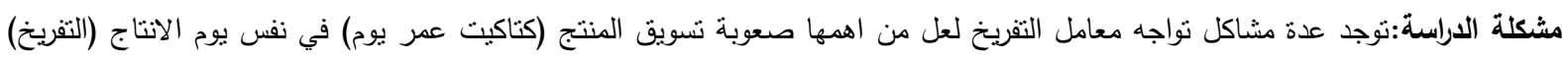

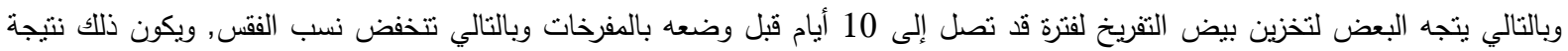

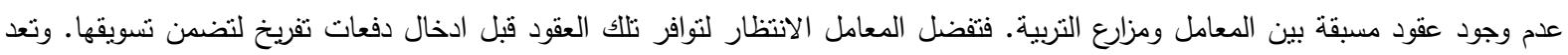

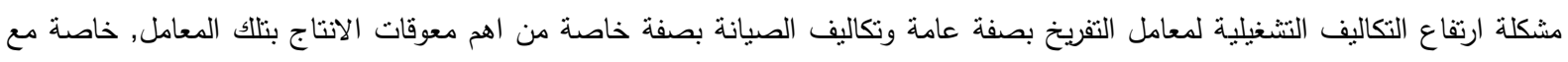

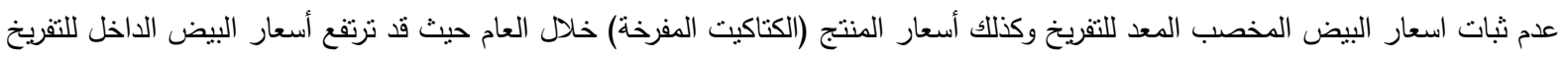
وتتخفض أسعار الكتاكيت, وبالتالي تتعرض المعامل لخسائر كبيرة.

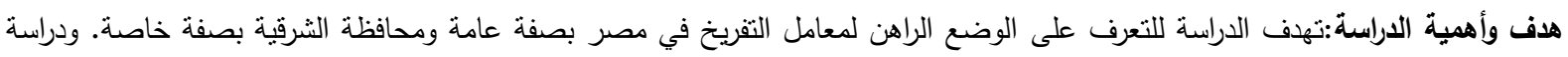
المشاكل التي نواجه تنلك المعامل لرفع كفاءتها الفنية والاقتصادية.

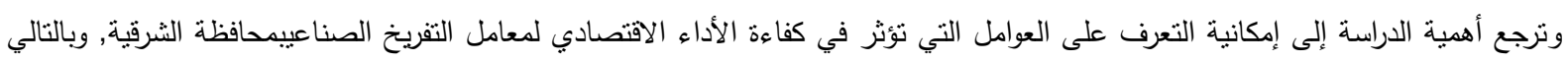
يمكن تقعيل وتتشيط العوامل الإيجابية وتثبيط وتحجيم العوامل السلبية.

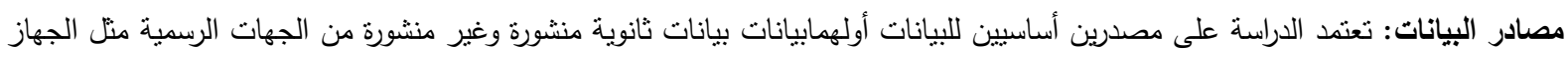

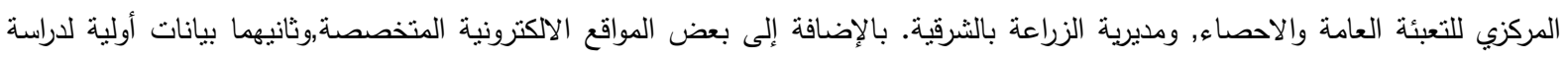

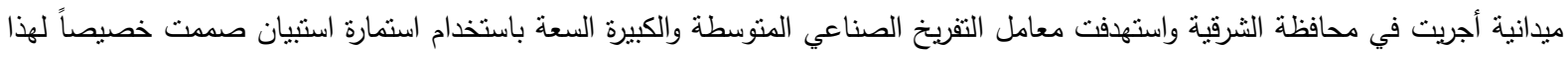

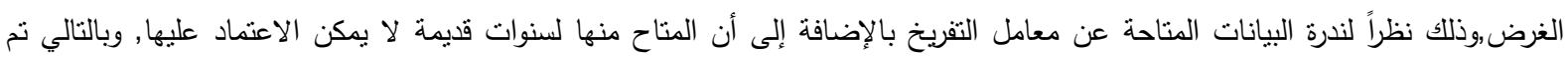

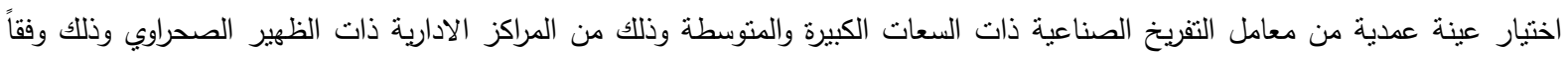

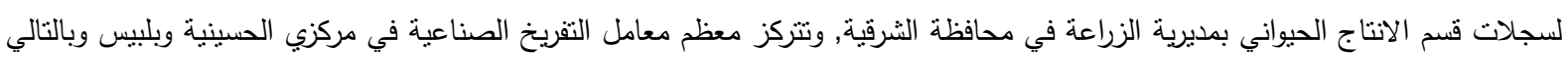
تم التركيز على هذين المركزين, وتم أخذ العينة من معامل مرخصة. وبلغ فئر حجم عينة الدراسة 60 معملاً. 
الأسلوب والطريقة البحثية: تعتد الدراسة في تحليل البيانات وعرض ما تتوصل إليه من ننائج على الأسلوبين الوصفي والكمي متمثلاً في معدل

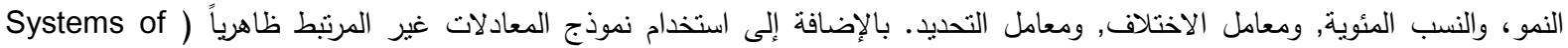
Seemingly UN Related Equation نبذه عن معامل التفريخ في مصر:التفريخ(5) هي العملية التي يتم بها دفع الجنين داخل البيضة على النمو والتطور بتوفير مختلف احتياجاته الطبيعية التي نساعده على ذلك طوال المدة التي تنتهي بنكوين فرخ جديد قادر على الخروج من البيضة والاعتماد على نفسه. وينت توفير دلفي

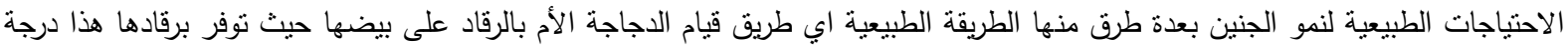
الحرارة والرطوبة اللازمة لنمو الجنين فضلاً عن قيامها بنهوية البيض وتقليبه بطريقة فطرية وهو ما يعرف بالئن بالتقريخ الطبيعي. ومنها الطريقة الصناعية أي ينم وضع البيض المراد تفريخه في اجهزة خاصة تسمى بالمفرخات صمدت بطريقة يمكن معها توفير احتياجات الجنين من حرارة

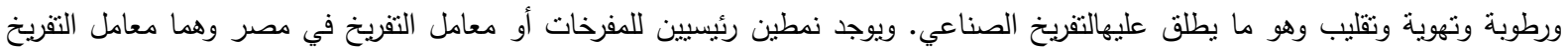

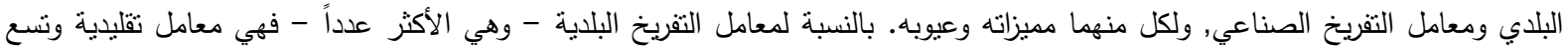

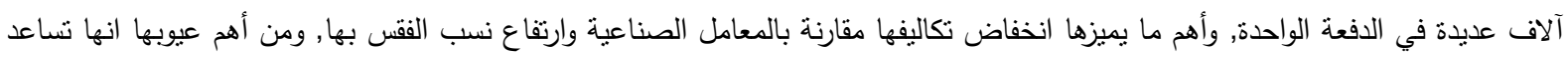

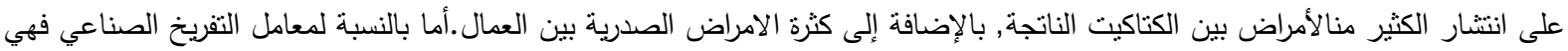

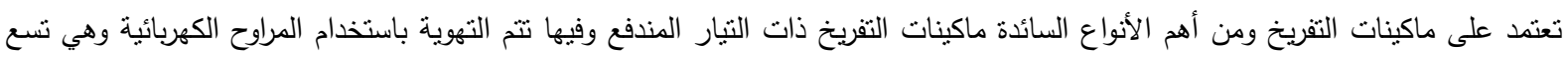
أكثر من 100 ألف بيضة في الدفعة الواحدة.

النتائج ومناقثتنها:

الملامح العامة لمعامل التفريخ في مصر ومحافظة الثرقية:

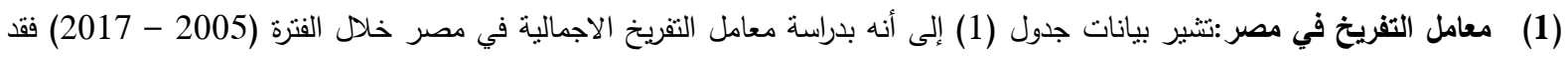
تيين أن متوسط عددها بلغ حوالي 1210,54 معمل, وبلغ الانخفاض السنوي في عدد المعامل خلال نلإلك الفترة حوالي 2.

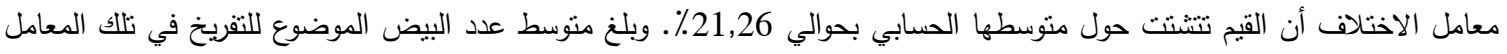
خلال فترة الدراسة حوالي 1160,81 مليون بيضة وبلغ معدل النمو السنوي لعدد البيض حوالي 5\%, وتوضح قيمة معامل الاختلاف أن

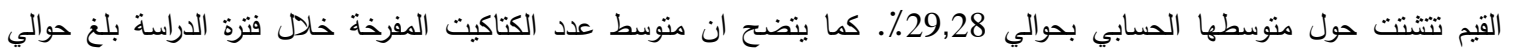
902,35 مليون كتكوت, وبلغ متوسط معدل الفقس حوالي 77,73٪. وبلغ معدل النمو السنوي لعدد الكتاكيت المفرخة حوالي 5 5. قيمة معامل الاختلاف أن القيم تتثتت حول متوسطها الحسابي بحوالي 33,02٪.

جدول 1. الملامح العامة لمعامل التفريخ في مصر ومحافظة الثرقية خلال الفترة (2005 - 2017) .

\begin{tabular}{|c|c|c|c|c|c|c|c|c|c|c|}
\hline \multicolumn{3}{|c|}{ معامل التفريخ الصناعي } & \multicolumn{3}{|c|}{ معامل التفريخ البلاي } & \multicolumn{3}{|c|}{ إجمالي معامل التفريخ } & \multirow[b]{2}{*}{ البيان } & \\
\hline $\begin{array}{c}\text { الاختلاف } \\
\text { معامل } \\
\text { (\%) }\end{array}$ & $\begin{array}{l}\text { النمول } \\
\text { (\%) }\end{array}$ & متوسط الفترة & $\begin{array}{c}\text { الاختلاف } \\
\text { (\%) }\end{array}$ & $\begin{array}{l}\text { النمول } \\
\text { (\%) }\end{array}$ & متوسط الفترة & 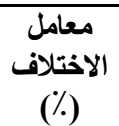 & $\begin{array}{l}\text { النمول } \\
\text { (\%) }\end{array}$ & متوسط الفترة & & \\
\hline 22,46 & 6 & 290,46 & 27,73 & $4-$ & 882 & 21,26 & $2-$ & 1210,54 & عدد المعامل & \\
\hline $\mathbf{3 4 , 5 5}$ & 6 & 1047,39 & 63,20 & 3- & 113,46 & 29,28 & 5 & 1160,81 & للتفريخ (بالمليون) الموضوع & $\bar{q}$ \\
\hline 37,84 & 6 & 818,44 & 68,21 & $2-$ & 83,91 & 33,02 & 5 & 902,35 & (بالمليون) الكتاكيت المفرخة & . \\
\hline - & 6 & 78,14 & - & - & 74,34 & - & - & 77,73 & معدل الفقس (\%) & \\
\hline 55,24 & - & 66,23 & 43,58 & 3- & 86,77 & 37,92 & 2 & 146,08 & عدد المعامل & \\
\hline- & 9 & - & - & - & $\mathbf{9 , 8 4}$ & - & - & 12,07 & \% من الجمهورية . & \\
\hline 82,75 & 8- & 222,48 & 27,71 & 2- & 9,72 & 45,62 & 9 & 185,10 & للتفريخ (بالمليون) الموضوع & g. \\
\hline - & - & 21,24 & - & - & 11,58 & - & - & 15,94 & \% من الجمهورية ـ . . . & $\sqrt[3]{3}$ \\
\hline 51,64 & 10 & 124,94 & 32,88 & 4- & 7,26 & 43,80 & 9 & 137,21 & (بالمليون) الكتاكيت المفرخة & "ד? \\
\hline - & - & 15,26 & - & - & 8,65 & - & - & 15,20 & \% من الجمهورية & \\
\hline - & - & 56,16 & - & - & 74,69 & - & - & 83,45 & معدل الفقس (\%) & \\
\hline
\end{tabular}

المصدر: جمعت وحسبت من بيانات الجهاز المركزي للتعبئة العامة والاحصاء, النشرة السنوية لإحصاءات الثروة الحيوانية, أعداد متفرقة. 


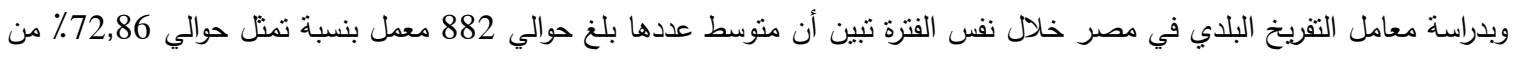

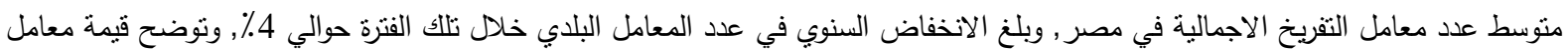

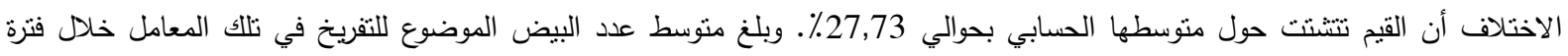

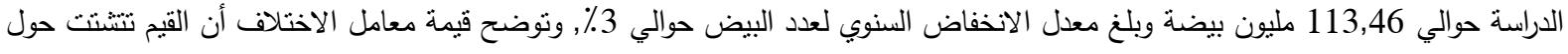

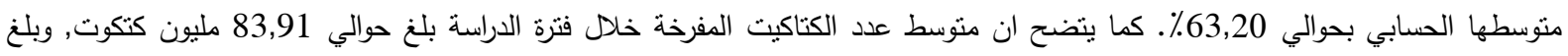

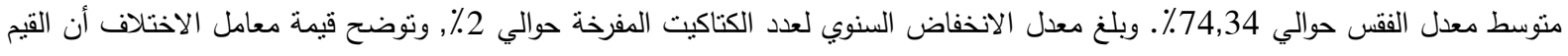

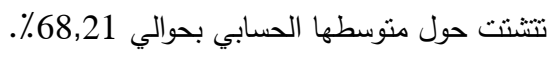
أما بدراسة معامل التفريخ الصناعي في مصر خلال نفس الفترة تنين أن متوسط عددها بلغ حوالي 290,46 معمل بنسبة تمثل حوالي 27,14٪

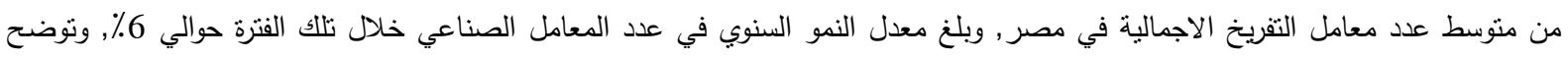

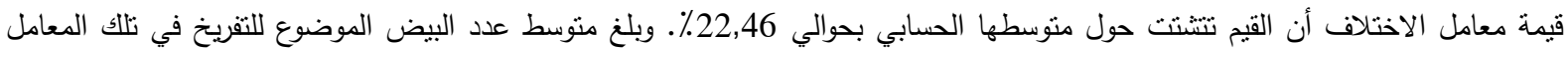

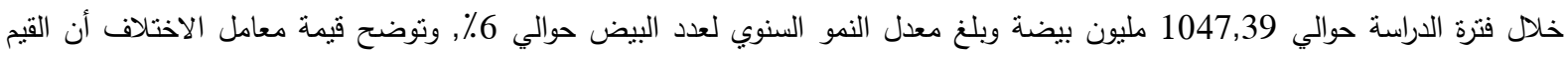

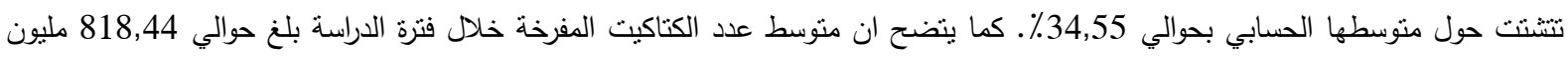

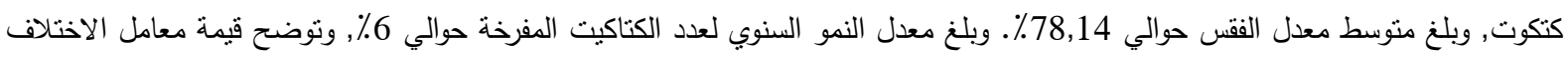

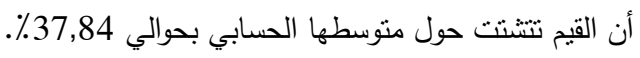

(2) معامل التفريخ بمحافظة الثرقية: يشير جدول (1) إلى أنه بدراسة معامل التفريخ الاجمالية في محافظة الثرقية خلال الفترة (2005 -

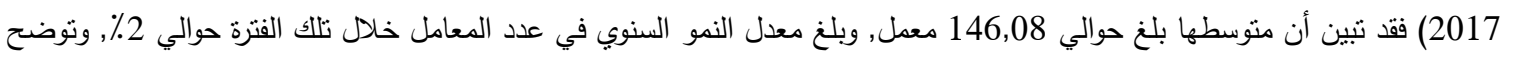

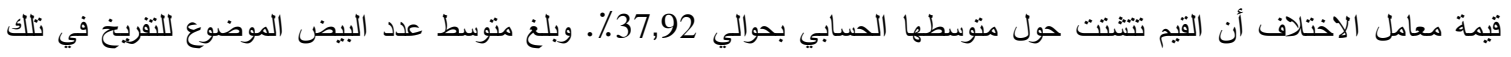

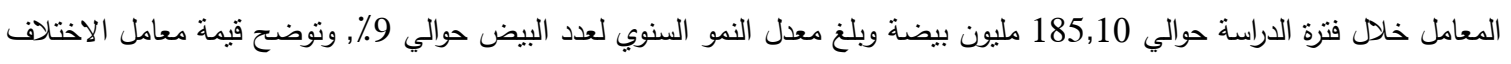

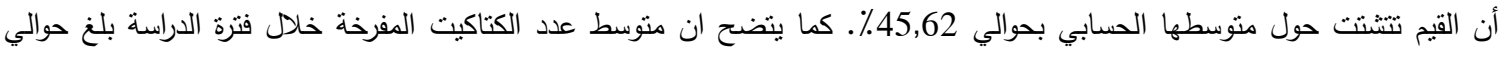

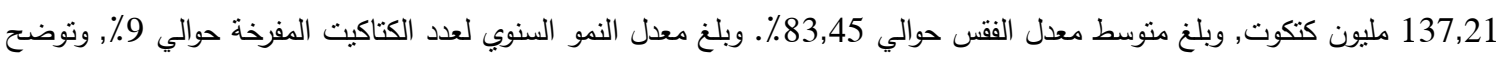

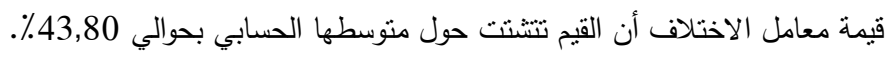

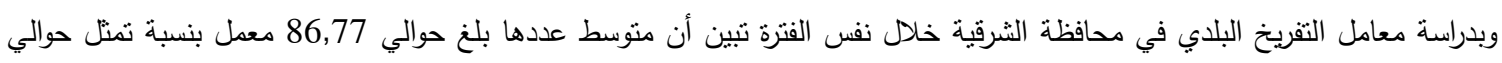

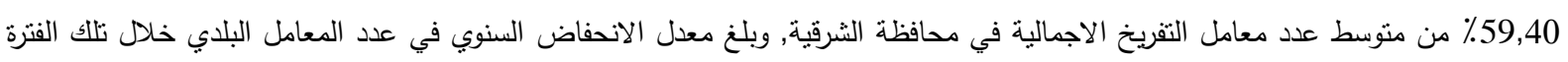

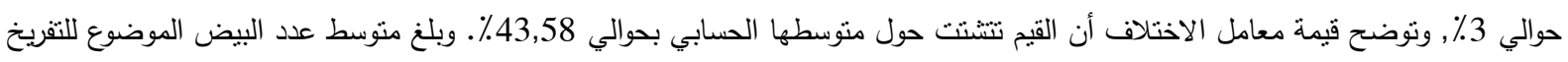

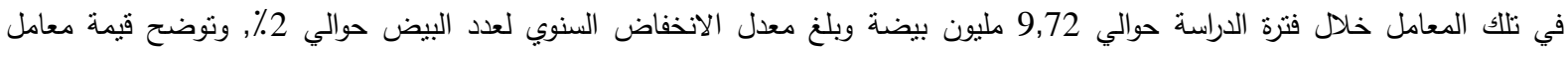

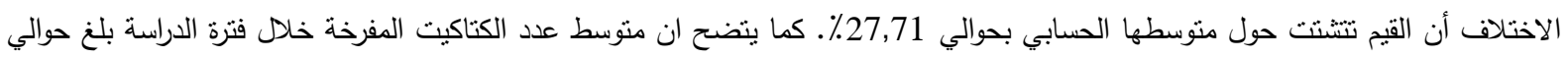

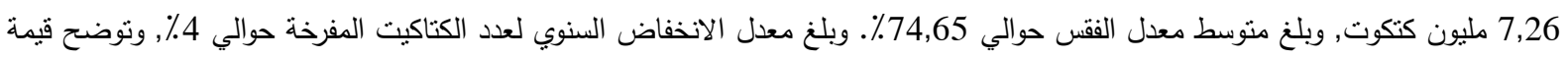

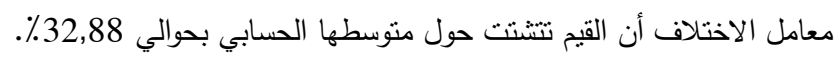

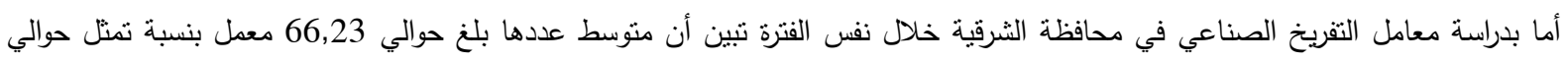

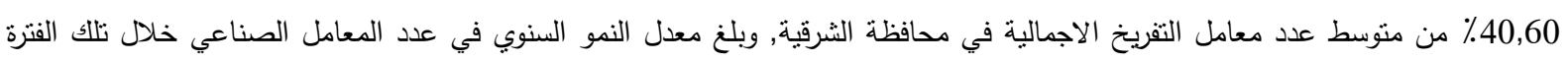

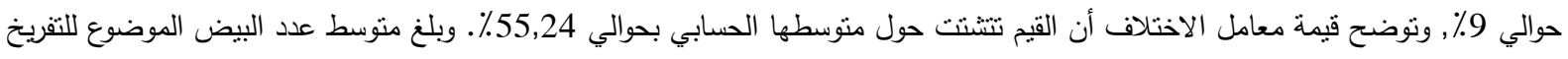

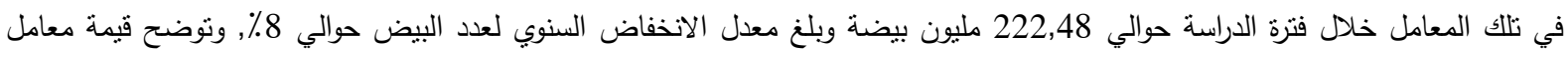

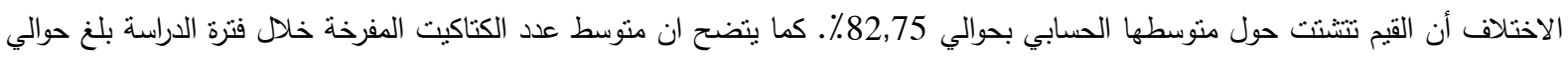

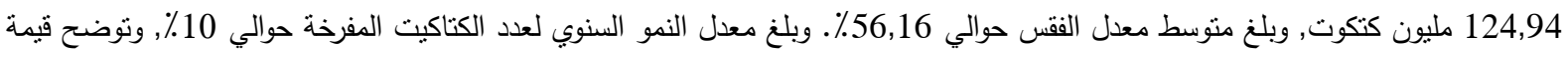

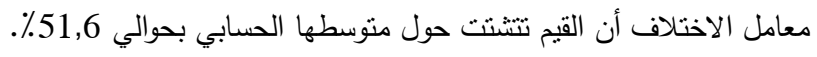

الخصائص والسمات العامة لمعامل التفريخ بعينة الدراسة:

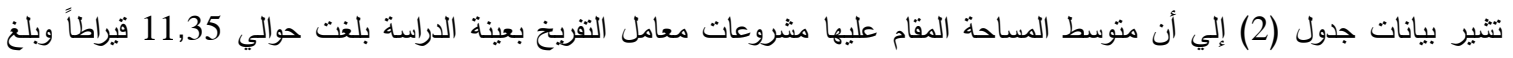

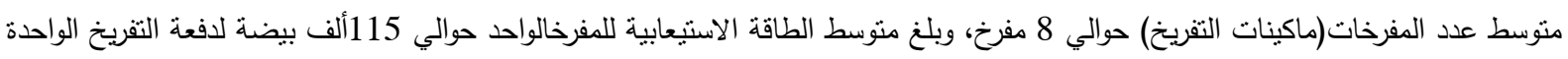

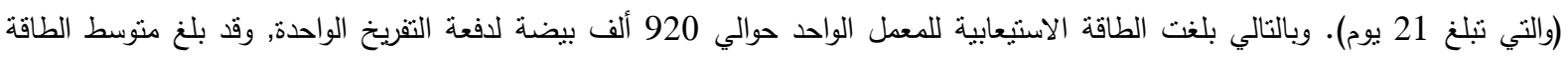

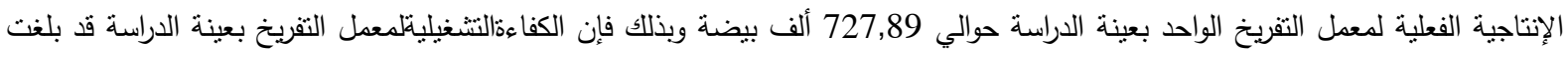
حوالي 79,12٪، وأن نسبة الطاقة المعطلةبه قد بلغت حوالي 20,88٪ من اجمالي الطاقة الاستيعابية للمعل. 
جدول 2. الخصائص والسمات العامة لمعامل التفريخ بعينة الدراسة المبدانبة بمحافظة الثرقية لعام2019.

\begin{tabular}{|c|c|c|c|}
\hline معامل الاختلاف (\%) & المتوسط & الوحدة & 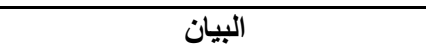 \\
\hline 31,75 & 11,35 & قير اط & مساحة الأرض المقام عليها المشروع \\
\hline 1,14 & 8 & مفرخ & متوسط عدد المفرخات في المعل \\
\hline 4,66 & 115 & ألف بيضة/للاورة & الطاقة الاستيعابيةتللمفرخً الواحد \\
\hline 3,22 & 920 & ألف بيضة/للاورة & الطاقة الأستيعابية للمعمل \\
\hline 5,91 & 727,89 & ألف بيضة/للاورة & الطاقة الفعلية للمعمل \\
\hline \multirow[t]{2}{*}{-} & 79,12 & $\%$ & نسبة التشغيل بالمعمل \\
\hline & 20,88 & $\%$ & نسبة الطاقة المعطلة \\
\hline
\end{tabular}

المصدر: حسبت من بيانات استمارات الاستبيان لعينة الراسة الميدانية لعام 2019.

التكاليف التأسيسية لمعامل التفريخ بعينة الدراسة:

يحتاج انشاء معمل للتفريخ الصناعي إلى تكاليف تأسيسية عالية, حيث بلغ متوسط تلك التكاليف لإنشاء مفرخ متوسط الحجم يستوعب حوالي 8 مفرخات بعينة الدراسة حوالي 10,03 مليون جنيه. وقسمت تلك التكاليف إلى أربعة اقسام وهي التكاليف الانثائية وتكاليف الأدوات الخدمية وتكاليف أجهزة التكييف وأخيراً نكاليف الانشاءات الكهربية. ويشير جدول (3) إلي متوسط التكاليف الإنشائية للمشروع بعينة الدراسة بلغت حوالي 5,61 مليون جنيهاً,وهي تشمل تكلفة إنشاء المبني بالإضافة إلى نكلفة المفرخات.كما بلغ منوسط تكاليف الأدوات الخدمية بعينة الدراسة حوالي 303,41 جنيه,وهي نشمل نكاليف كل من: (ماكينات الغسيل

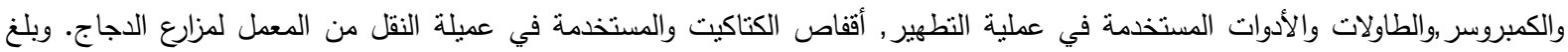
منوسط تكاليف أجزة التكييفحوالي 831,41 ألف جنيهاً, وهي تثمل تكاليف كل من: (المكيفات,النشلر ,الثفاطات). وأخبراً تكاليف الإنشاءات الكهربائية وبلغ متوسطها حواليط3,32 مليون جنيهاً وهي تتمثل في تكلفة كل من: (المولد الكهربائي, والإمدادات واللوحات الكهربائية).

\begin{tabular}{|c|c|c|c|c|}
\hline معامل الاختلاف (\%) & المتوسط & الوحدة & البيان & نوع التكاليف \\
\hline 31,04 & 1541,18 & ألف جنية & تكلفة المبني & \multirow{4}{*}{ التكاليف الإنشائية } \\
\hline 31,04 & 7,71 & مفرخ & عدد المفرخات & \\
\hline 52,77 & 558,82 & ألف جنية & ثمن المفرخات & \\
\hline 60,97 & 4073,53 & ألف جنية & إجمالي تكلفة المفرخات & \\
\hline 33,62 & 6,95 & ألف جنية & أقفاص كتاكيت & \multirow{5}{*}{ تكاليف الأدوات } \\
\hline 25,70 & 14,76 & ألف جنية & ترابيزات وادوت تطهير & \\
\hline 34,16 & 263,41 & ألف جنية & ماكينة غسيل & \\
\hline 89,74 & 18,24 & ألف جنية & كمبروسر (1) & \\
\hline 78,87 & 303,41 & ألف جنية & إجمالي تكاليف الأدوات الخدمية & \\
\hline 20,35 & 45,29 & ألف جنية & 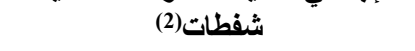 & \multirow{4}{*}{ تكاليف أجهزة } \\
\hline 32,39 & 547,06 & ألف جنية & مكيفات(3) & \\
\hline 68,06 & 247,06 & ألف جنية & تشلر (4) & \\
\hline 59,96 & 839,41 & ألف جنية & إجمالي تكاليف أجهزة التكييف & \\
\hline 142,82 & 465,71 & ألف جنية & الامدادات واللوحات الكهربائية & \multirow{3}{*}{ الإلشرباءاتية } \\
\hline 115,97 & 2855,04 & ألف جنية & مولد كهربائي & \\
\hline 100,25 & 2855,04 & ألف جنية & إجمالي تكاليف الانشاءات الكهربائية & \\
\hline 45,44 & 10023,62 & ألف جنية & ي التكاليف الر أسمالية & \\
\hline
\end{tabular}

(1)الكمبروسر : ضاغط الهواء ويستخدم في دفع الهواء تدريجياً لخفض الضغط في المكان.

$$
\begin{aligned}
& \text { (2) الثفاطات: التي تتقل العادم خارج المعمل والمكيفات }
\end{aligned}
$$

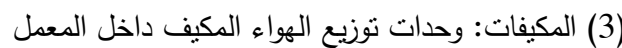

(4) التشلر : الجهاز المستخدم في خفض درجة حرارة الماء المستخدم في عملية التبريد

(5) المولد الكهربائي: مصدر نيار كهربائي احتياطي يعمل في حالة انقطاع التبار الكهربائي

المصدر: حسبت من بيانات استمارات الاستبيان لعينة الدراسة الميدانية بمحافظة الثرقية لعام 2019. 


\section{المتغيرات الفنية لمعامل التفريخ بعينة الدراسة الميدانية:}

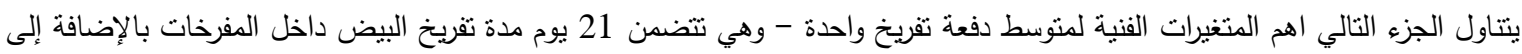

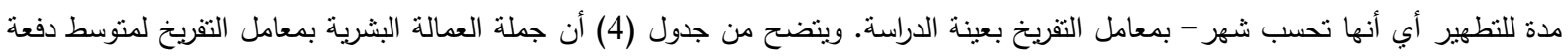
واحدة بعينة الدراسة الميدانية بلغ منوسطها حوالي 16,35 فرد (وهي تثمل كلا من المهندسين والفنيين والعمال). وبلغت متوسط طاقة التخزين الفعلية بالمعمل 115 ألف بيضة. وبلغت أطول مدة لنخزين البيض بليض بالمعامل 5,71 يوم. ومن الجدول تبين أن الدفعة الواحدة تشتهلك حوالي

سم من المطهرات.

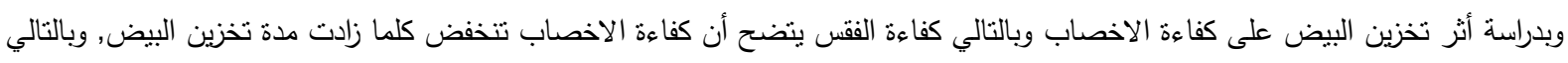

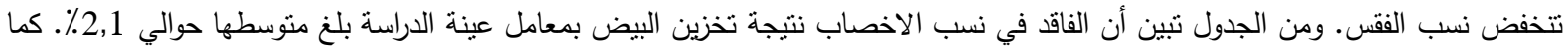

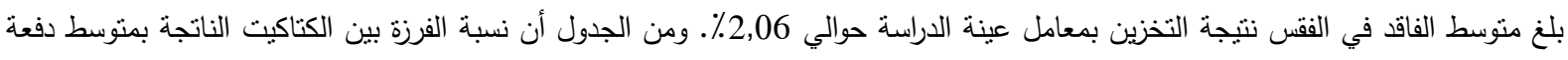
بمعامل التفريخ في عينة الدراسة بلغت حوالي 0,94٪.

جدول4. المتغيرات الفنية لمعامل التفريخ لمتوسط دفعة واحدة بعينة الدراسة الميدانية بمحافظة الثرقية لعام 2019.

\begin{tabular}{|c|c|c|c|c|}
\hline معامل الاختلاف (\%) & المتوسط & 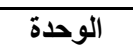 & المتغير & \\
\hline $\mathbf{7 , 3}$ & 3,18 & عدد & عدد المهندسين & \\
\hline 5,9 & 11,76 & عدد & عدد العمال & \\
\hline 7,1 & 1,41 & عدد & عدد الفنيين & العماده البترية \\
\hline- & 16,35 & عدد & جملة العمالة البشرية & \\
\hline 8,78 & 115 & ألف بيضة & طاقة التخزين الفعلية بالمعمل & \\
\hline 7,08 & 5,71 & يوم & أطول مدة للتخزين & كقاءوة التخزين \\
\hline 10,49 & 5,5 & سم & استهلاك الدفعة من المطهرات & عملية التطهير \\
\hline- & 85 & $\%$ & \% للإخصاب (البيض الطازج) & \\
\hline - & 82,9 & $\%$ & \% للإخصاب (للبيض المخزون) & \\
\hline - & 2,1 & $\%$ & الفاقُ المخزوني في الإخصاب & كأعاءة الاخصاب \\
\hline 9,65 & 107,5 & ألف بيضة & عدد البيض الغير "مخصَب (الطازج) & \\
\hline 5,25 & 620,4 & ألف بيضة & عدد البيض الغير مخصب (المخزون) & \\
\hline - & 82,06 & $\%$ & \% الفقس (بيض طازج) & \\
\hline - & 80 & $\%$ & \% الفقس (بيض مخزون) & كفاوة الفقس للبيض \\
\hline - & 0,94 & $\%$ & \% للكتاكيت الفرزة & \\
\hline
\end{tabular}

أثر العمليات التي تجرى يومياً داخل معامل التفريخ على نسب الفقس بعينة الاراسة:

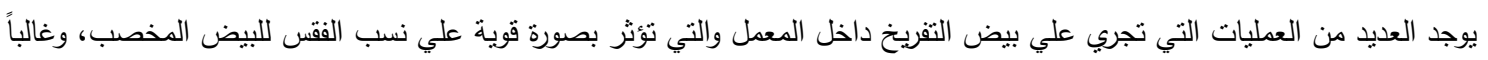

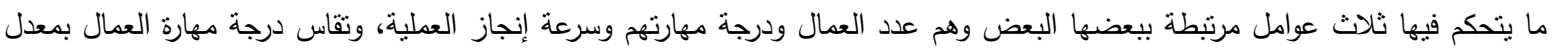

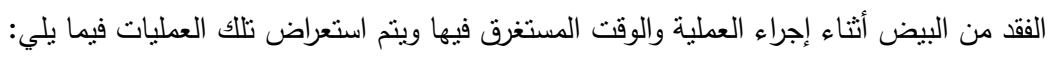
1- - استقبال ورص البيض:وفي هذه العملية يتم استقبال البيض الوارد من مزارع امهات التسمين داخل معطل التفريخ واعداده للارص داخل

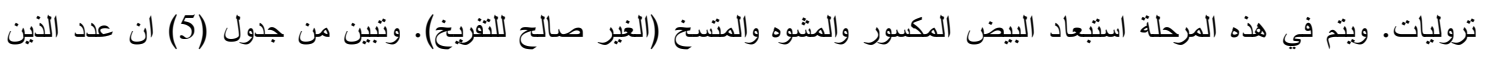

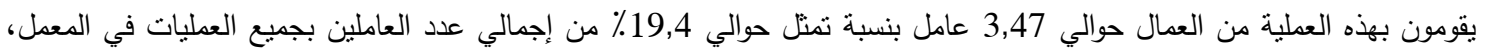

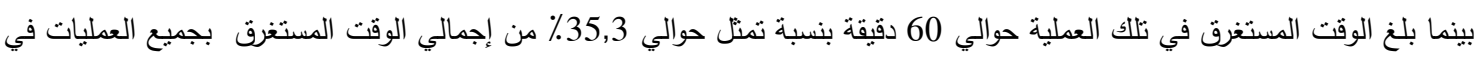

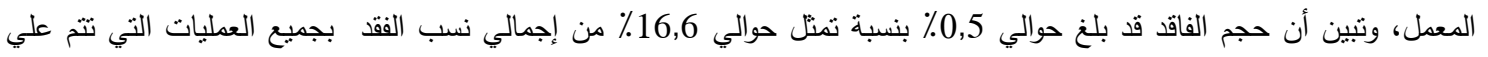

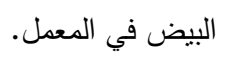

2- الكثف الضوئي: وفي هذه العملية يتم استخراج البيض من الحضانات بعد عمر 8 يوم ومروره علي مصدر ضوئي للكثف عن حالة الأجنة الموجودة داخل البيض واستبعاد البيض الذي يخترقه الضوء(بيض غير مخصب), وتحديد نسب الإخصاب من خلال القانون التالي:

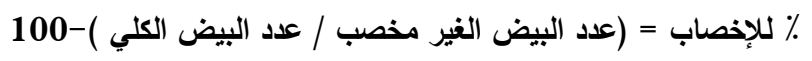

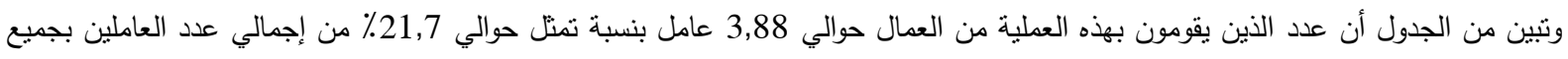

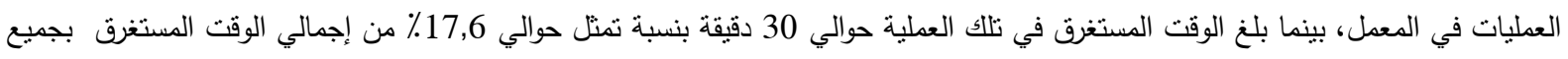


العمليات في المعمل، وتبين أن حجم الفاقد قد بلغ حوالي 1,17٪ بنسبة نمثل حوالي 38,7٪ من إجمالي نسب الفقد بجميع العمليات التي تتم علي

جدول 5. أثز العمليات التي تجري يومياً داخل معامل تفريخ كتاكيت التسمين علي نسب الفقس بعينة الدراسة الميدانية بمحافظة الثرقية لعام

.2019

\begin{tabular}{|c|c|c|c|c|c|}
\hline معامل الاختلاف (\%) & $\%$ & المتوسط & الوحدة & البيان & نوع العملية \\
\hline 17,99 & 19,4 & 3,47 & عامل & عدد العمال & \\
\hline- & 35,3 & 60 & دقيقة & مدة العملية & استقبال ورص \\
\hline 37,10 & 16,6 & $\mathbf{0 , 5 0}$ & $\%$ & حجم الفاقد & \\
\hline 20,12 & 21,7 & 3,88 & عامل & عدد العمل & \\
\hline - & 17,6 & 30 & دقيقة & مدة العملية & الكثف الضوئي \\
\hline $\mathbf{3 5 , 8 8}$ & 38,7 & 1,17 & $\%$ & حجم الفاقت & \\
\hline 25,06 & 17,5 & 3,12 & عامل & عدد العمال & \\
\hline- & 23,5 & 40 & دقيةة & مدة العملية & عملية النقل \\
\hline 35,28 & 13,6 & 0,41 & $\%$ & حجم الفاقد & \\
\hline 10,93 & 41,3 & 7,38 & عامل & عدد العمال & \\
\hline- & 23,5 & 40 & دقيقة & مدة العملية & عمليه القرر \\
\hline 31,04 & 31,1 & 0,94 & $\%$ & حجم الفاقّة & \\
\hline 74,1 & 100 & 17,85 & عامل & عدد العمال & \\
\hline- & 100,0 & 170 & دقيقة & مدة العملية & الإجمالي \\
\hline 139,3 & 100,0 & 3,02 & $\%$ & حجم الفاقً & \\
\hline
\end{tabular}

3- عملية النقل: وفي هذه العملية يتم استخراج البيض من الحضانات ونقله في صواني تتاسب عملية الفقس في ماكينات اخري (مفقسات)

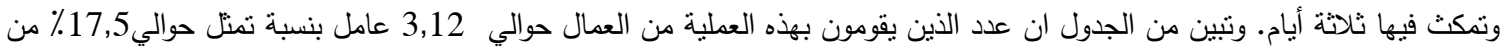
إجمالي عدد العاملين بجميع العمليات في المعمل، بينما بلغ الوقت المستغرق بجنئ بنيع العمليات في المعمل، وتبين أن حجم الفاقد قد بلغ حوالي 0,41\% بنسبة تمثل حوالي 13,6٪ من إجمالي نسب الفقد بجميع العمليات التي تتم علي البيض في المعمل. 4 - عملية الفرز والتحميل:وفي هذه العملية يتم فرز وعد الكتاكيت الناتجه من بيض التفريخ ووضعها في عبوات مناسبة ويتم نقلها لمزارع

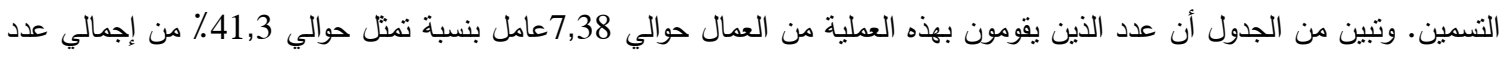

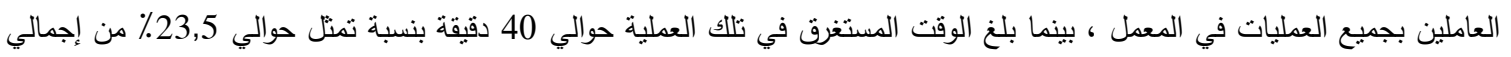

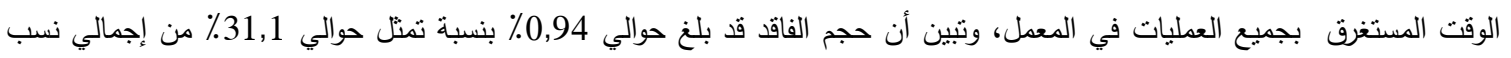
الفقد بجميع العمليات التي تتم علي البيض في المعمل. 5- إجمالي عمليات المعمل: تبين أن عدد العمال الذين يقومون بالعمليات المختلفة التي تجري علي بيض التي التفريخ داخل المعمل قد بلغ حوالي

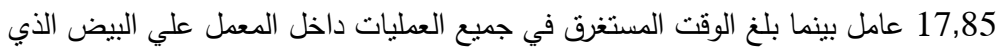
يتم تفريخه يومياً حوالي 170 دقيقة وأن إجمالي نسب الفقد من بيض التفريخ يبلغ حوالي 3,02٪.

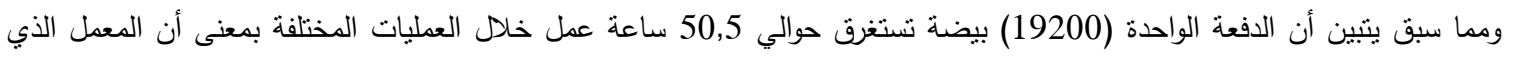
طاقته دفعة واحدة يومياً يحتاج إلى عدد من العمال يبلغ حوالئرة 6,3 عامل يومياً وأن متوسط أجر العامل في اليوم 56 جنيهاً، كما أن حجم الفاقد

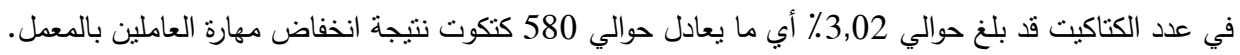
هيكل بنود التكاليف الانتاجيتفي معامل التفريخ بعينة الاراسة: وتثير بيانات جدول (6)إلى أن إجمالي التكاليف الانتاجيتلمنوسط دفعة تفريغ واحدة (شهر) بمعامل التفريغ بعينة الدراسة الميدانية لعام 2019 قد بلغ حوالي 238 ألف جنيه،والتي قسمت اللى قسمين الأول ويتمثل في التكاليف التشغيلية وبلغت حوالي 152,22 ألف جنيه/دفعة تمنل حوالي 64٪من إجمالي التكاليف الإنتاجية للمعمل. والثاني ويتمنل في إيجار المعمل (ما يخص الدفعة الواحدة من الايجار) والذي بلغ حوالي 85,75

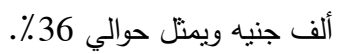


جدول 6. بنود التكاليف الإنتاجيتلمعامل التفريخ وأهيتها النسبية بعينة الدراسة الميدانية خلال دفعة تفريخ واحدة (ثهر) بمحافظة الثرقية لعام .2019

\begin{tabular}{|c|c|c|c|c|}
\hline معامل الاختلاف & $\%$ & جنيه/دورة & البنود & \multirow{6}{*}{ العمل البشري } \\
\hline 3,50 & 8,98 & 14240 & مهندسين & \\
\hline 5,90 & 8,31 & 19770 & عمالة عادية & \\
\hline 6,80 & 1,29 & 3060 & عمالة فنية & \\
\hline 4,30 & 15,60 & 37070 & إجمالي العمل البشري & \\
\hline 21,03 & 0,29 & 700 & تكلّفة التخزين & \\
\hline 15,12 & 0,08 & 179 & تكلفة التطهير للبيض المخزون & \multirow[t]{2}{*}{ عملية التخزين } \\
\hline 20,25 & $\mathbf{0 , 3 7}$ & 879 & جملة تكلفة التخزين & \\
\hline 48,65 & 7,29 & 17353 & الصيانة & \multirow{10}{*}{ تكاليف تثغيلية } \\
\hline 43,94 & 2,99 & 7114 & الفرشة والكرتون & \\
\hline 34,22 & 0,95 & 2257 & المنظفات & \\
\hline 45,33 & 35,10 & 83422 & الكهرباء & \\
\hline 40,91 & 0,44 & 1053 & المياه & \\
\hline 30,76 & 0,26 & 610 & مصاريف مكتبية & \\
\hline 32,32 & 0,26 & 607 & تنقلات & \\
\hline 52,44 & 0,80 & 1910 & مصروفات نثرية & \\
\hline 44,85 & 48 & 114276 & جملة التكاليف التشغيلية الاخرى & \\
\hline 38,65 & 64 & 152225 & الاجمالي & \\
\hline 45,44 & 36 & 85750 & \multicolumn{2}{|c|}{ الايجار (ما يخص الدفعة من الايجار السنوي) } \\
\hline- & 100 & 237975 & جملة التكاليف & \\
\hline
\end{tabular}

بنود الإيرادات في معامل التفريخ بعينة الدراسة الميدانية:

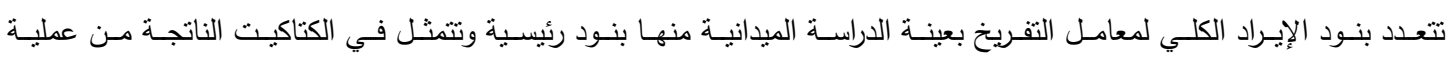

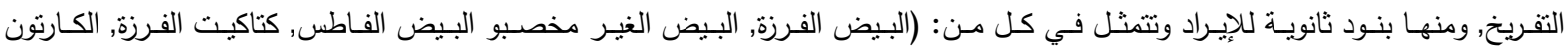

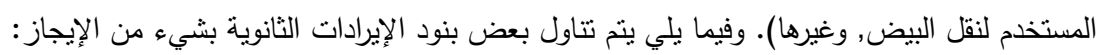

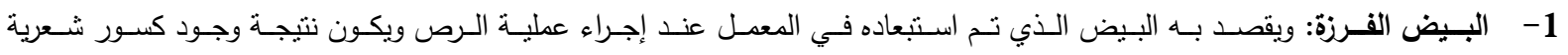

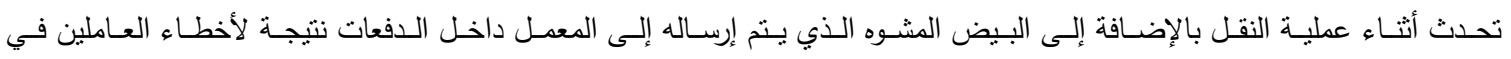
المزرعة أو في محاولة للحصول منه على كتاكيت ولو بنسبة منخفضة وذلك نتيجة ارتفاع أسعار الكتاكيت.

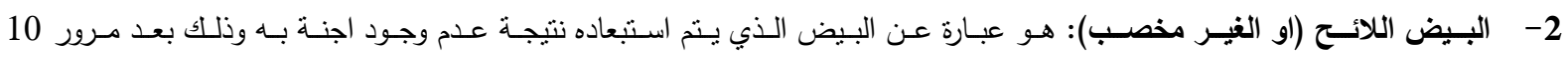

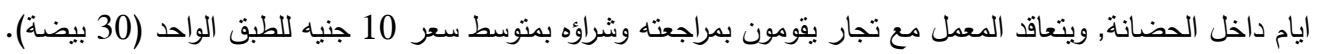

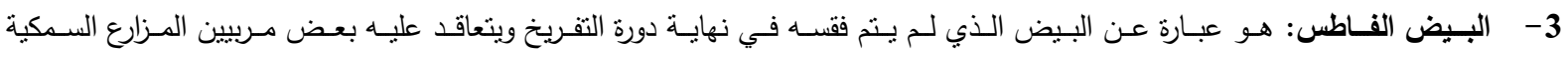
ومزارع البط بمتوسط سعر 35 جنيه للألف بيضة.

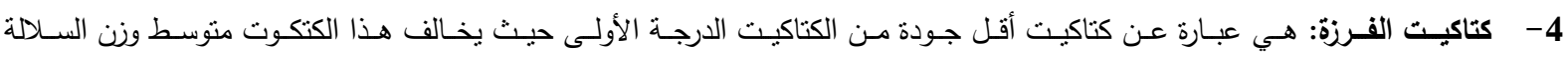

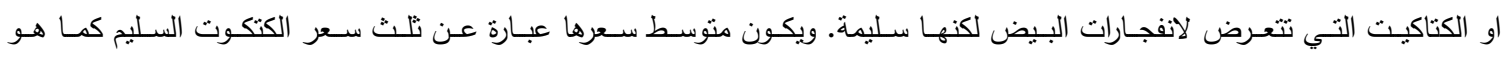
منعارف عليه في المعامل.

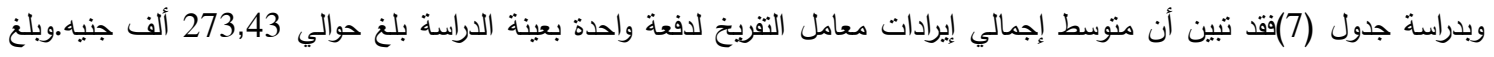

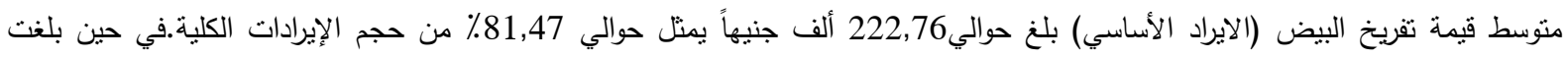
إيرادات النواتج الثانوية حوالي 50,67 ألف جنيه تمنل حوالي 18,13٪ من حجم الايرادات الكلية. 
جدول 7. بنود الإيرادات الكليةلمتوسط دفعة تفريخ واحدة بمعامل التفريخ بعينة الدراسة الميدانية بمحافظة الثرقية للعام 2019.

\begin{tabular}{|c|c|c|c|c|}
\hline معامل الاختلاف & $\%$ & متوسط الإيراد (بالجنيه) & البنود & \\
\hline 5,78 & 81,47 & 222760 & قيمة تفريخ البيض & الايراد الاساسي \\
\hline 8,08 & 10,09 & 27585 & ايراد بيعالبيض الغير مخصب(1) & \\
\hline 5,21 & 5,45 & 14917,50 & إيرادات الفرزة (2) & \\
\hline 4,17 & 1,86 & 5094,20 & إيراد بيعالبيض الفرزة(3) & \\
\hline 7,37 & $\mathbf{0 , 8 1}$ & 2203,33 & إيراد بيع البيض الفاطس(4) & الاير ادات الثانوية \\
\hline 5,82 & 0,26 & 707 & إيراد مبيعات الكرتون & \\
\hline 3,04 & $\mathbf{0 , 0 6}$ & 160,83 & إيرادات اخري & \\
\hline 5,52 & 18,53 & 50667,86 & جملة الإيرادات الثَانوية & \\
\hline 4,59 & 100 & 273427,86 & إجمالي الإيرادات & \\
\hline
\end{tabular}

المصدر: حسبت من بيانات استمارات الاستبيان لعينة الدراسة الميدانية لعام 2019.

مؤشرات كفاعة الأداء الاتّصادية بمعامل التفريخ بعينة الدراسة الميدانية: يوضح جدول (8) أن إجمالي التكاليف الكلية لمتوسط دورة تفريخ واحدة بمعامل التفريخ بعينة الدراسة (شهر ) بلغت حوالي 238 ألف جنيهاً, حيث بلغت قيمة الايجار لمتوسط دفعة تفريخ واحدة حوالي 85,75ألف جنيهاً، بينما بلغت التكاليف النتغيلية حوالي 152,22ألف جنيهاً.وبلغ الإيراد الكلي لمنوسط دفعة التفريخ بلغ حوالي 273,43 ألف جنيهاً ليصبح بذلك صافي العائد حوالي 35 الف جنيهاً.كما بلغت ربحية الجنيه المستثمر حوالي 0,15 جنيه, وهذا يعني أن الجنيه المستثمر قادر علي تحقيق 15٪ من قيمته كعائد سنوي عند استثماره في معامل التقريخ لمدة شهر (دفعة تفريخ واحدة). وبلغت نسبة الايراد الكلي إلى التكاليف الكلية حوالي 1,15. وبلغت نسبة الايراد الكلي إلى التكاليف التشغيلية حوالي 1,80. 1,8 وأخيراً

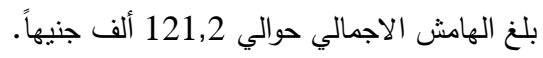
جدول 8. مؤشرات الكفاءة الاقتصادية لمتوسط دفعة تفريخ واحدة (شهر) بمعامل التفريخ بعينة الدراسة الميدانية في محافظة الثرقية لعام 2019.

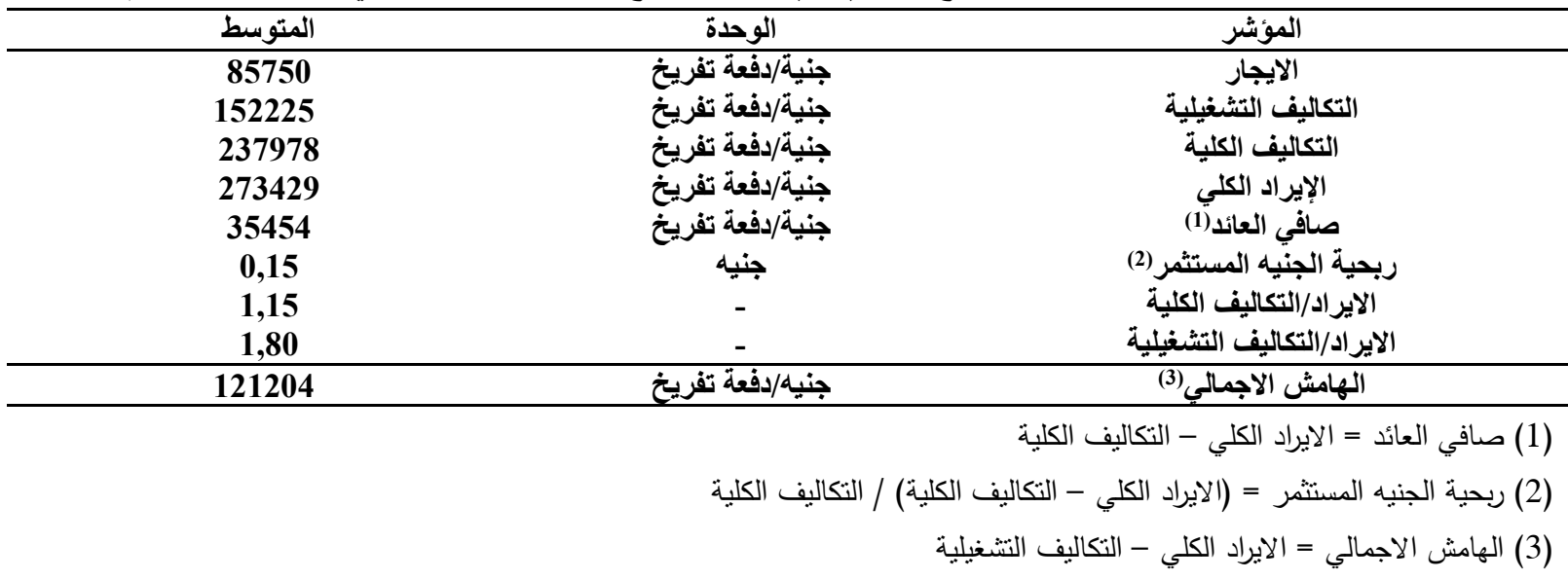

المصدر: حسبت من بيانات استمارات الاستبيان لعينة الدراسة الميدانية لعام 2019.

تقدير النموذج القياسي لكفاعة الأداء الاقتصادي والفني لمعامل التفريخ بعينة الدراسة الميدانية:

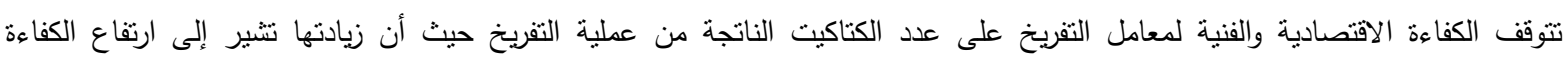
وانخفاضها يثبر إلى انخفاض الكفاءة. ولقياس تلك الكفاءة فقد اجريت عدة محاولات لتقدير عدة صور رياضية, وقد تبين ان أكثر تللك الصور Systems of ) تمشياً مع طبيعة البيانات المتحصل عليها وأكثرها دق احصائياً ومنطقية اقتصادية نموذج المعادلات غير المرتبطة ظاهرياً (SURE)(Seemingly UN Related Equation المتحصل عليها إلى النتائج التالية: تشير معادلة (1) بجدول (9) إلى وجود علاقة طردية موجبة معنوية احصائياً بين عدد البيض الداخل للتفريخ وبين عدد المفرخات بالمعامل بعينة

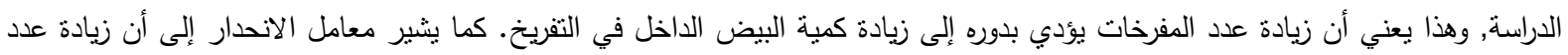
المفرخات بمقدار وحدة واحدة يؤدي إلى زيادة القدرة الاستيعابية للمفرخات (أي عدد البيض الداخل للتفريخ) بمقدار معامل التحديد والذي بلغ 0,71 إلى أن المتغير الثارح المستقل (عدد معامل التفريخ) يفسر حوالي 71٪ من التغير في المتغير التابع (عدد 
البيض الداخل في التفريخ), أما الباقي (29٪) يرجع إلى عوامل أخرى غير مدروسة. ويؤكد ما سبق قيمة (F) المحسوبة حيث بلغت حوالي

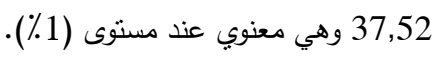

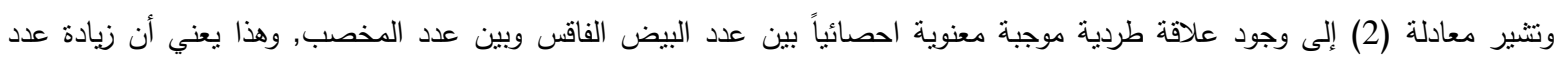

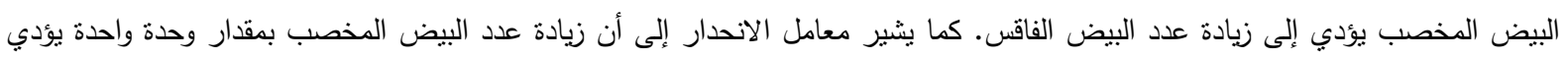

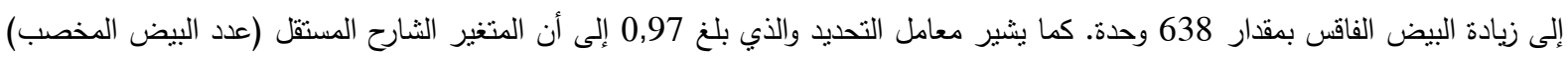

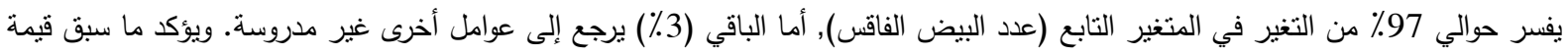

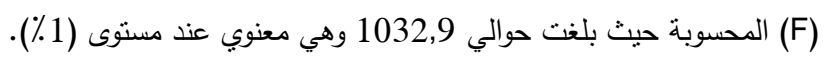

جدول 10. نموذج المعادلات الغير مرنبطة ظاهرياً لقياس كفاءة معامل التقريخ بعينة الدراسة المبدانية للعام 2019.

\begin{tabular}{|c|c|c|c|c|c|c|c|c|c|}
\hline معنوية النموذج (F) & $\mathbf{R}^{2}$ & & & ل لات & & & & البيان & b \\
\hline 37,52 & 0,71 & س1هـ & $\begin{array}{r}13329,5 \\
* * \\
(6,125)\end{array}$ & + & $\begin{array}{l}299272- \\
(1,709-)\end{array}$ & $=$ & ص1هـ & العلاقة بين كمية البيض الداخل & 1 \\
\hline 1032,9 & 0,97 & س2هـ & $\begin{array}{c}\mathbf{0 , 6 8 9} \\
* * * 132,140)\end{array}$ & + & $\begin{array}{l}63087,38 \\
* *(3,349)\end{array}$ & $=$ & ص2هـ & والعلاقة بين عدد البيض المخب الفاقس & 2 \\
\hline 460,6 & 0,96 & س3هـ & $\begin{array}{c}0,638 \\
* *(21,462)\end{array}$ & + & $\begin{array}{r}8662,29 \\
* * \\
(3,167)\end{array}$ & $=$ & ص3هـ & العلاقة بين عدد الكتاكيت المباعة & 3 \\
\hline
\end{tabular}

صاه= القيمة التقديرية لعدد البيض الداخلة في عملية التقريخ في المشاهدة هـ. ص2ه= القيمة التقديرية لعدد البيض الفاقس في المشاهدة هـ.

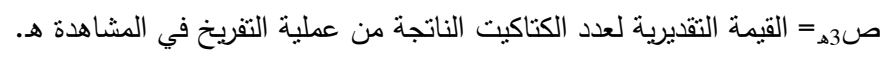

$$
\begin{aligned}
& \text { س1هـ عدد المفرخات في المعمل في المشاهدة هـ. } \\
& \text { س2ه= عدد البيض المخصب في المشاهدة هـ. } \\
& \text { س3ه= عدد البيض الفاقس في المشاهدة هـ. }
\end{aligned}
$$

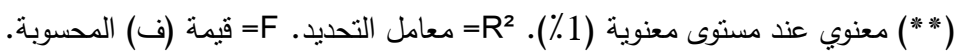

المصدر: حسبت من بيانات استمارة الاستبيان لعينة الدراسة الميدانية لعام 2019.

كما تثير معادلة (3) إلى وجود علاقة طردية موجبة معنوية احصائياً بين عدد الكتاكيت الناتجة بعد الفرز والمعدة للبيع وبين عدد البيض

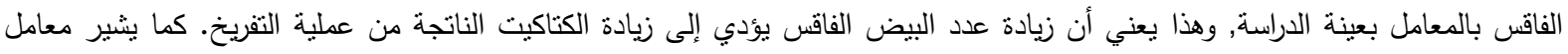
الانحدار إلى أن زيادة عدد البيض الفاقسبمقار وحدة واحدة يؤدي إلى زيادة الكتاكيت الناتجة السليمة بعد الفرز والمعد للبيع بمقدار 638 وحدة.

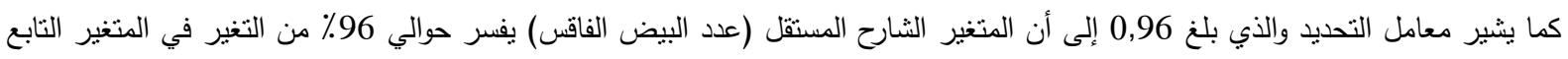
(عدد الكتاكيت المعدة للبيع), أما الباقي (4) يرجع إلى على عوامل أخرى غير مدروسة. ويؤكد ما سبق قيمة (F) المحسوبة حيث بلغت حوالي

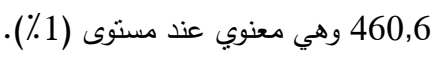
المنطق الاقتصادي للنتائج:في الوقت الذي تتوقف فيه الكفاءة الاقتصادية والفنية لمعامل التقريخ بعينة الدراسة الميدانية على عدد الكتاكيت السليمة الناتجة من عملية التفريخ والمعدة للبيع, فقد تبين أنها تتوقف على عدد البيض الفاقس والذي يتوقف بدوره على عدد البيض المخصب. كما لفا أن عدد البيض الداخل في عملية التفريخ يتوقف على عدد المفرخات بمعامل التفريخ. ومما سبق يتضح أنف أنف البيانات الواردة بالدراسة مطابقة لنتائج التحليل

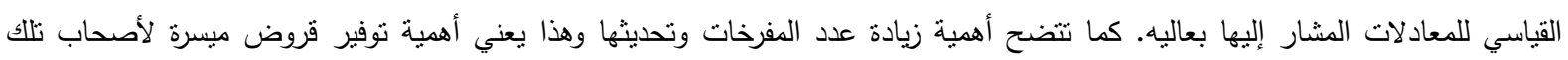

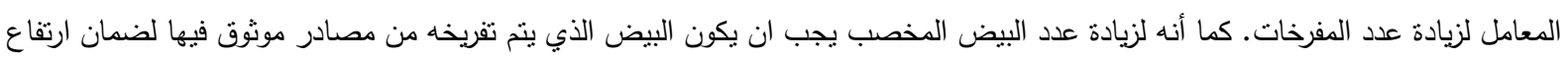

$$
\text { نسب الاخصاب. }
$$

المشاكل والمعوقات التي تواجه معامل تفريخ كتاكيت التسمين بعينة الدراسة الميدانية:

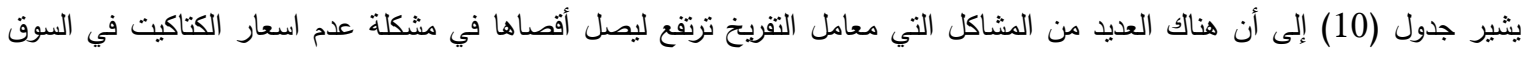
وبالتالي قد تتعرض المعامل للخسارة نتيجة ارتفاع تكاليف التفريخ وانخفاض العائد من بيعها يمنل حوالي 15,87٪ من إجمالي المشاكل والمعوقات

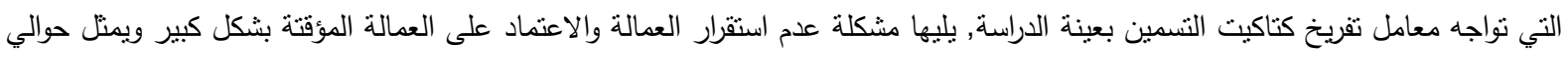
15,34\%, ثم يليها مشكلة ندرة الخبرات اللازمة لمجال التفريخ يمثل حوالي 14,81\%, وتتخفض لتصنل أدناها في مشكلة عدم وجود وسائل 
لاستخدام مخلفات التفريخ (قثر البيض)في التصنيع وصعوبة التخلص منه ويمنل حوالي 3,71٪ من إجمالي المشاكل والمعوقات التي تواجه مزارع أمهات دجاج التسمين بعينة الدراسة.

جدول 10. أهم المشاكل التي نواجه معامل التفريخ بعينة الدراسة الميدانية في محافظة الشرقية لعام 2019.

\begin{tabular}{|c|c|c|}
\hline التكرار النسبي (\%) & 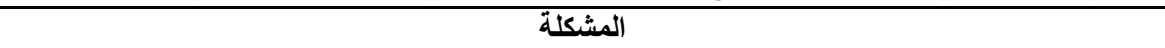 & م \\
\hline 15,34 & عدم استقرار العمالة & 1 \\
\hline 14,81 & ندرة الخبرات في هذا المجال & 2 \\
\hline 13,23 & عدم وجود مراكز تدريبية للعاملين & 3 \\
\hline 4,42 & زيادة نسبة الفاقد في العمليات المختلفة للتفريخ & 4 \\
\hline 10,17 & ارتفاع تكاليف الطاقة المستخدمة في التشغيل والتَّي تستحوذ علي ما يقرب من نصف العائد المتحصل عليه & 5 \\
\hline 8,58 & ارتفاًع تكاليف الصيّاتة في المفرخًات الحديثة & 6 \\
\hline 15,87 & عدم استقرار أسعار الكتاكيت في الأسواق & 7 \\
\hline 7,52 & ارتفاع أسعار المواد الخام المستخدمة في الإنتاج من الفرشة و المنظفات والمطهرات وصناديق تحميل & 8 \\
\hline 6,35 & ارتفاع تكاليف النقل & 9 \\
\hline 4,71 & عدم وجود وسنائل لاستخدام مخلفات التفريخ (قشر البيض)في التصنيع وصعوبة التخلص منه & 10 \\
\hline 100 & 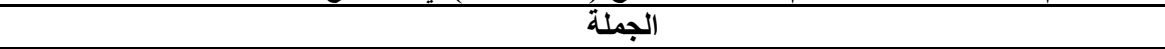 & \\
\hline
\end{tabular}

المصدر: حسبت من بيانات استمارات الاستبيان لعينة الدراسة الميدانية لعام 2019.

وسائل رفع كفاءة الأداء لمعامل تفريخ كتاكيت التسمين بعينة الدراسة الميدانية:

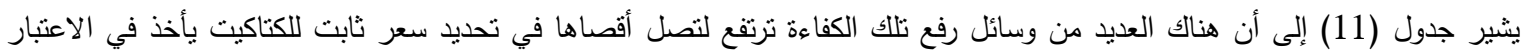
تكاليف الإنتاج بالإضافة إلى هامش ربح ويمثل حوالي 32,74٪ من جملة وسائل رفع كفاءة أداء معامل تفريخ كتاكيث النسمين من وجهة نظر

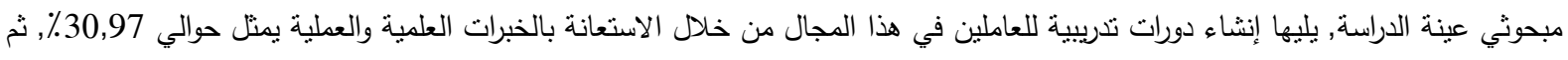

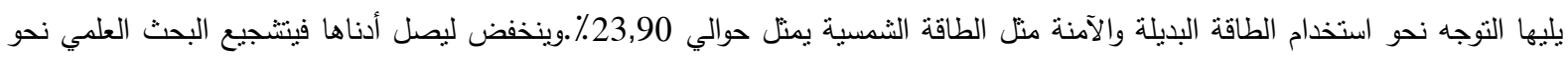
استخدام مخلفات التفريخ بطريقة آمنة صديقة للبيئة ويمنل حوالي 3,54٪ من جملة وسائل رفع كفاءة أداء مزارع أمهات دجاج التسمين من وجهة نظر مبحوثي عينة الدراسة.

جدول 11. وسائل رفع كفاءة الأداء لمعامل تفريخ كتاكيت التسمين بعينة الدراسة الميدانية في محافظة الثرقية لعام 2019.

\begin{tabular}{|c|c|c|}
\hline 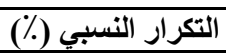 & الوسائل & ? \\
\hline 30,97 & إنشاء دورات تدريبية للعاملين في هذا المجال من خلال الاستعانة بالخبرات العلمية والعملية & 1 \\
\hline 23,90 & التوجه نحو الطاقة البديلة والآمنة التي يتم توليدها من المخلفات مثل البيوجاز وكذلك المولدة من طاقة الرياح & 2 \\
\hline $\begin{array}{l}32,74 \\
8,85 \\
3,54\end{array}$ & 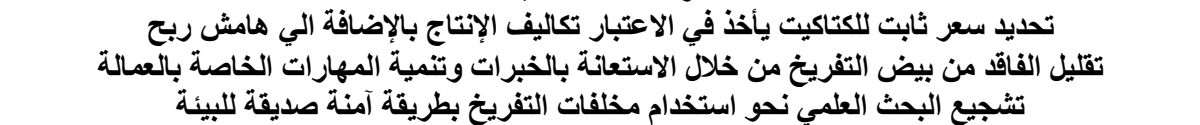 & $\begin{array}{l}3 \\
4 \\
5\end{array}$ \\
\hline 100 & الجملة & \\
\hline
\end{tabular}

المصدر: حسبت من بيانات استمارات الاستبيان لعينة الاراسة الميدانية لعام 2019.

استهدفت الدراسة التعرف على الوضع الراهن لمعامل التفريخ في مصر بصفة عامة ومحافظة الشرقية بصفة خاصة. ودراسة المشاكل التي

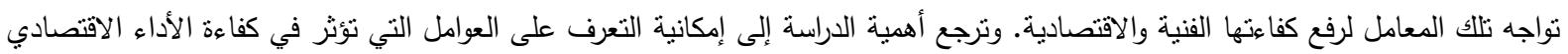

لمعامل التفريخ الصناعيبمحافظة الثرقية, وبالتالي يمكن تفعيل وتتشيط العوامل الإيجابية وتثبيط وتحجيم العوامل السلبية.

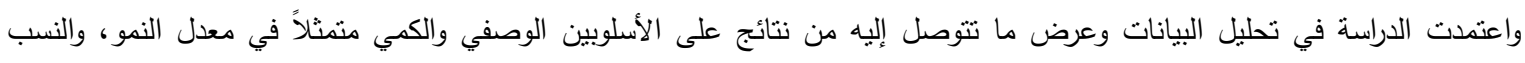

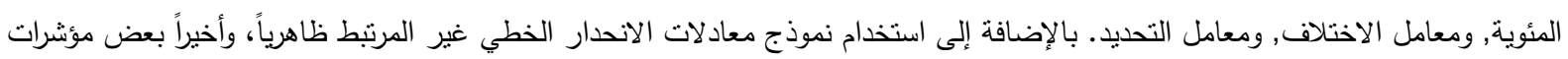
الكفاءة الاقتصادية الإنتاجية. كما اعتمدت الدراسة على مصدرين أساسيين للبيانات أولهمابيانات أولية لدراسة ميدانية أجريت في محافظة الثرقية واستهدفت معامل التفريخ الصناعي المتوسطة والكبيرة السعة باستخدام استمارة استبيان صممت خصيصاً لهذا الغرض.وثانيهما بيانات ثانوية منشورة وغير منشورة من الجهات الرسمية مثل الجهاز المركزي للتعبئة العامة والاحصاء, ومديرية الزراعة بالثرقية. بالإضافة إلى بعض المواقع الالكترونية المتخصصة. 


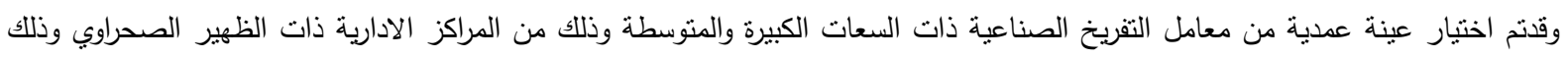

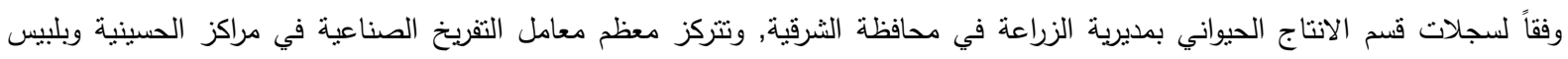
وبالتالي تم التركيز على هذين المركزين. وتم أخذ العينة من معامل مرخصة وأخرى غير مرخصة على ملى حد سواء. وبلغ حجم عينة الدراسة 60 معملاً. وقد توصلت الدراسة إلى عدة نتائج من أهمها: أنهبدراسة متوسط المساحة المقام عليها المعل تبين أنها بلغت حوالي 11,35 قيراطاً بعدد مفرخات

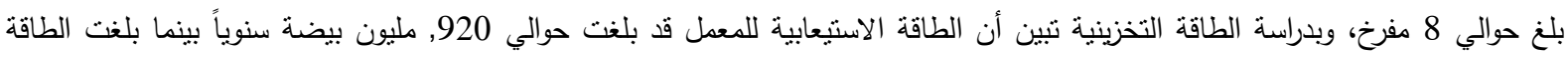

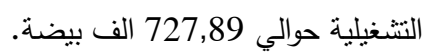

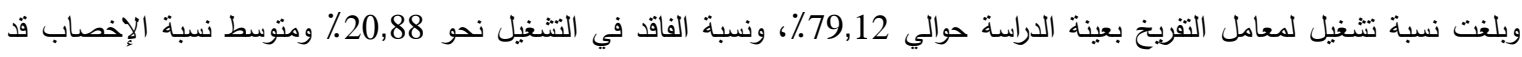

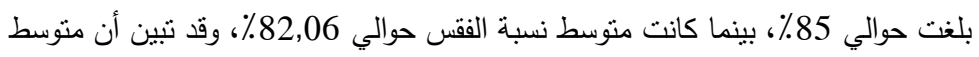
نسبة الفرزه قد بلغت حوالي 0,94\%، وهو ما يثير إليانخفاض كفاءة عملية التقريخ.

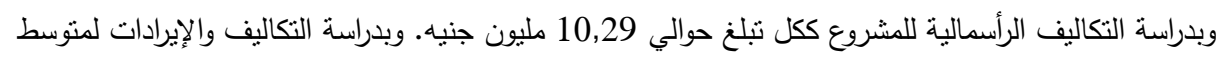

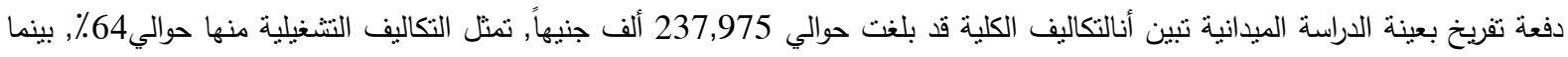

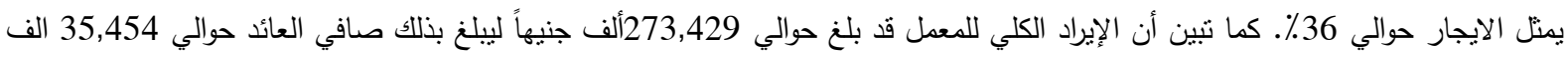

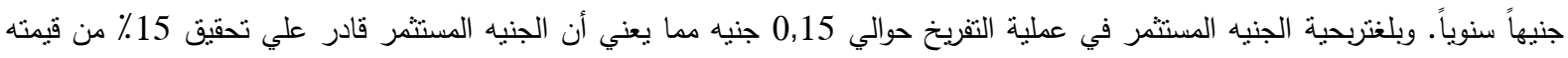

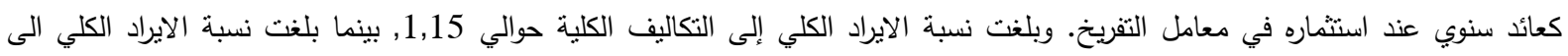

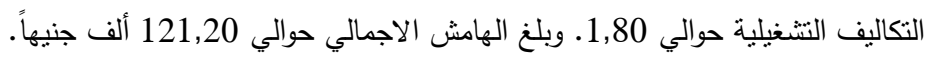

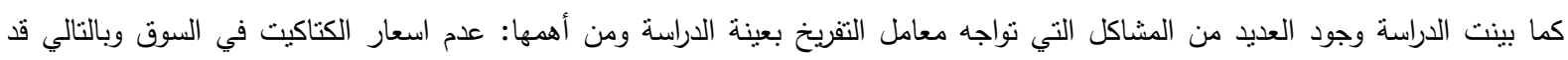

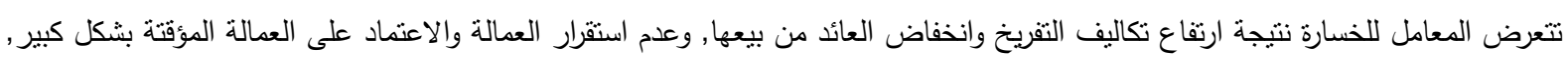
وندرة الخبرات اللازمة لمجال التفريخ.

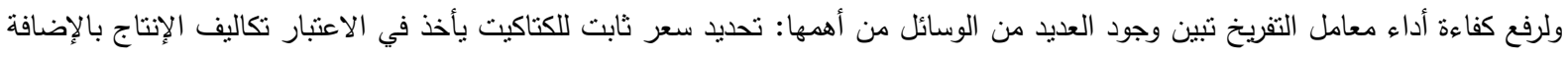

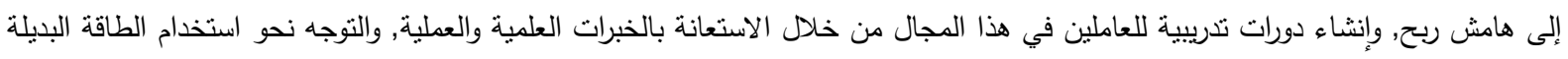

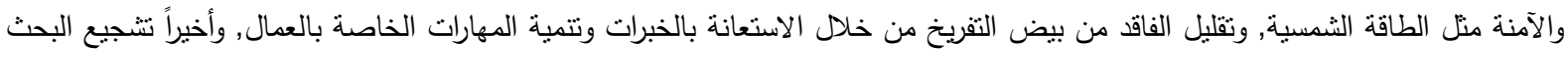

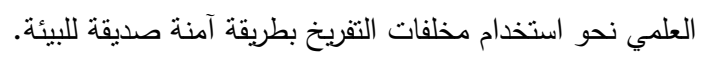
وتأسيساً على ما سبق فإن الدراسة توصي بالآتي: 1- ضرورة أخذ وسائل رفع كفاءة معامل التقريخ والتي جاءت باءت بالدراسة في الاعتبار حيث أنها من وجهة نظر أصحاب المعامل بعينة الدراسة أي أنها من ارض الواقع.

2- وجود نظام للتعاقد بين مزارع أمهات الدواجن ومعامل التفريخ من جهة, وبين معامل التفريخ ومزارع الدواجن من جهة أخرى.

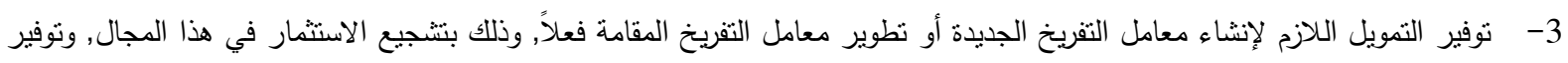
قروض بفوائد ميسرة وفترات سماح للسداد.

المراجع

- - أحمد عطية محمد شحاته: دراسة اقتصادية لإنتاج وتسويق مزارع امهات ومعامل تفريخ دجاج التسمين بمحافظتي الثرقية والاسماعيلية,

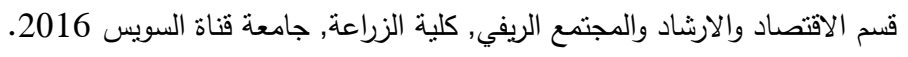
2- أيمن زيدان عبد الحميد زيدان: اقتصاديات صناعة الدواجن في مصر , رسالة دكتوراه, قسم الاقتصاد الزراعي, كلية الزراعة, جامعة عين

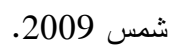

3- - الجهاز المركزي للتعبئة العامة والاحصاء, النشرة السنوية لإحصاءات الثروة الحيوانية, أعداد متفرقة.

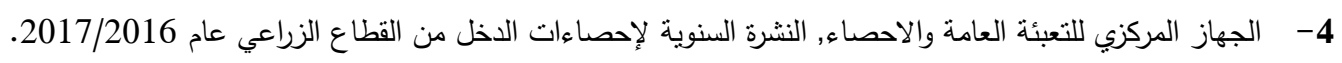

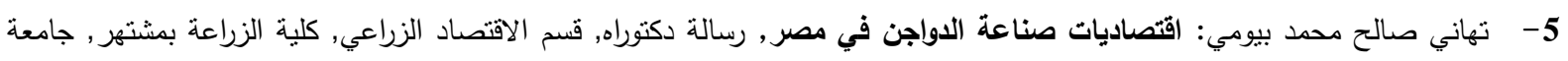
بنها 2012. 6- سامية محمد عبد الخالق العجوري (دكتور), جعفر محمود الجندي (دكتور): إنتاج وتربية الدواجن, كتاب بقسم الانتاج الديواني والداجني

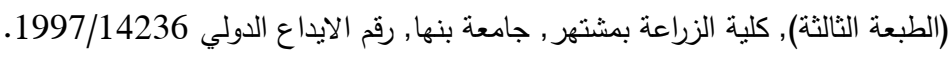

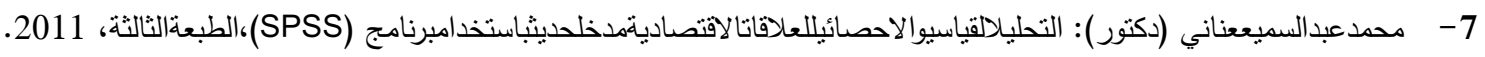




\title{
An Economic Study for Hatchery Plants in Sharkia Governorate
}

\author{
Dr. Tahany Saleh Mohamed Baumy Dr. Eman Rajab Hassan Soliman \\ Senior Researcher Researcher \\ Agricultural Economics Research Institute \\ Corresponding Author: Dr tahany_saleh@yahoo.com
}

\section{Summary:}

The study aimed to identify the current status of hatchery laboratories in Egypt in general and Sharkia Governorate in particular. And study the problems facing those laboratories to raise their technical and economic efficiency. The importance of the study is due to the possibility of identifying the factors that affect the efficiency of the economic performance of the industrial hatchery laboratories in Sharkia governorate, and thus positive factors can be activated and activated and discouraging and limiting negative factors.

The study relied on analyzing the data and presenting its findings on the descriptive and quantitative methods represented in the growth rate, percentages, coefficient of difference, and determining factor. In addition to using the apparently unrelated linear regression equations model, and finally some indicators of productive economic efficiency.

The study also relied on two main data sources, the first of which was primary data for a field study conducted in Sharkia governorate and targeting medium and large-scale industrial hatcheries using a questionnaire designed specifically for this purpose. The second is published and unpublished secondary data from official bodies such as the Central Agency for Public Mobilization and Statistics, and the Directorate of Agriculture in the East. In addition to some specialized websites.

An intentional sample of artificial hatchery plants of large and medium capacities was chosen from administrative centers with desert backs, according to the records of the Animal Production Department of the Directorate of Agriculture in the Sharkia Governorate. Most of the industrial hatchery plants are concentrated in the Husayniyah and Bilbeis centers, and therefore the two centers are focused on. The sample was taken from both licensed and unlicensed laboratories. The sample size of the study was 60 laboratories.

The study reached several results, the most important of which are: that by studying the average area on which the plant is located, it turned out that it amounted to about 11.35 carats with a number of hatcheries of about 8 hatcheries, and by studying the storage capacity it was found that the absorptive capacity of the plant reached about 920 million eggs annually while the energy reached Operating about 727,89 thousand eggs.

The employment rate for hatchery laboratories in the study sample was about $79.12 \%$, the percentage of lost employment is about $20.88 \%$, and the average fertilization rate has reached about $85 \%$, while the average percentage of hatching was about $82.06 \%$, and it has been shown that the average

The screening rate was about $0.94 \%$, which indicates the low efficiency of the hatching process.

And by studying the capital costs of the project as a whole, it amounts to about 10.29 million pounds. And by studying the average costs and revenues

Hatching batch with a field study sample shows that the total costs have reached about 237,975 thousand pounds, of which operating costs represent about $64 \%$, while rent represents about $36 \%$. It was also found that the total revenue of the factory amounted to about 273,429 thousand pounds, bringing the net return to about 35,454 thousand pounds annually. The profitability of the pound invested in the hatchery process was about 0.15 pounds, which means that the invested pound is able to achieve $15 \%$ of its value as an annual return when investing in the hatchery plant. The ratio of total revenue to total costs was about 1.15 , while the ratio of total revenue to operating costs was about 1.80 . The total margin was about 121.20 thousand pounds.

The study also revealed that there are many problems facing hatchery laboratories in the sample of the study, the most important of which are: the lack of chicks prices in the market, and therefore laboratories may be exposed to loss due to the high costs of spawning and the low return from their sale, the instability of employment and dependence on temporary labor significantly, and the scarcity of expertise required for the spawning field.

To raise the efficiency of hatchery performance, it was found that there are many methods, the most important of which are: setting a fixed price for chicks that takes into account production costs in addition to a profit margin, establishing training courses for workers in this field through the use of scientific and practical experiences, and orientation towards the use of alternative and safe energy such as solar energy, And reduce losses from hatchery eggs through the use of expertise and skills development for workers, and finally encourage scientific research towards the use of hatchery waste in a safe and environmentally friendly way. 